\title{
Undergraduate nursing students' belongingness in clinical learning environments: Constructivist grounded theory
}

\author{
Allison Kern ${ }^{1}$, Phyllis Montgomery ${ }^{2}$, Sharolyn Mossey ${ }^{2}$, Patricia Bailey ${ }^{2}$ \\ 1. Kingston Public Health Unit, Kingston, Ontario, Canada. 2. School of Nursing, Laurentian University, Sudbury, ON, \\ Canada.
}

Correspondence: Phyllis Montgomery. Address: School of Nursing, Laurentian University, Ramsey Lake Road, Sudbury, ON, Canada. Email: pmontgomery@laurentian.ca

Received: May 27, 2013

DOI : $10.5430 /$ jnep.v4n3p133
Accepted: September 21, 2013 Online Published: November 11, 2013

URL: http://dx.doi.org/10.5430/jnep.v4n3p133

\section{Abstract}

Background: Experiential learning within clinical practice settings is a substantial component of undergraduate nursing education. This study described baccalaureate nursing students' perception of how their belongingness evolves in clinical learning environments through partnerships with their clinical educator and unit-based nurses.

Methods: The design of this study was constructivist grounded theory. The setting was a single four year baccalaureate nursing program located in Ontario, Canada. Eighteen students enrolled in third or fourth year of the program participated in a total of 22 semi-structured one-to-one interviews. Comparative methods were used to analyze the data.

Results: The students' described positioning for belongingness, persevering for belongingness, and ultimately, entering into belongingness. Belongingness was depicted as gaining entry into the nursing "atmosphere", a privileged space unique to each clinical placement. In this space, students were granted access to rich learning and socialization opportunities in alliance with the unit-based nurses. For students unable to secure belongingness, learning within the clinical setting occurred as outsiders, exterior to the nursing atmosphere.

Conclusion: Students described belongingness as possible when their demonstrated competencies were validated by others who had the capacity to optimize their professional socialization and development within the clinical setting.

\section{Key words}

Undergraduate students, Clinical learning, Belongingness, Grounded theory, Education

\section{I ntroduction}

Nursing students are subject to an educational process that involves academic as well as clinical education. This means that in addition to their academic experiences, nursing students must progress through diverse clinical learning environments prior to graduation. These environments are viewed as integral components of nursing education, providing students with opportunities for integrating theory and practice, acquiring experiences and knowledge, and building values for professional practice ${ }^{[1,2]}$. Associated with such opportunities is the challenge of adapting to multiple contexts and new groups of professionals throughout their program of study ${ }^{[3]}$. 
Within the disciplines of psychology and education the concept of belonging has been examined within the context of student learning. Belonging has been defined as having a proper place in, being related to, and/or being a member of something deemed of importance to an individual ${ }^{[4-6]}$. Belonging is possible within learning environments that recognize a student's personhood. Further, evidence suggests that a student's subjective sense of belonging impacts learning behaviors and success in a program ${ }^{[7]}$.

Within nursing literature, the concept of belongingness has been examined in relation to student clinical education. Belongingness has been described as a fundamental human need associated with feelings, cognitions, and behaviours motivated by a desire for meaningful interaction and acceptance by valued others ${ }^{[8-14]}$. Positive partnerships between students and clinical educators facilitated learning through the completion of academic work, integration of feedback, and modeling the practice of experts ${ }^{[15]}$. Similarly, Gillespie ${ }^{[16]}$ found that students who perceived a positive relationship with their clinical educator engaged in nursing praxis through linkages between theoretical and clinical knowledge. In addition, Elcigil and Sari ${ }^{[17]}$ found that partnerships with nurses in mentoring roles increased students' belongingness by guiding learning, sharing praxis experiences, and clarifying expectations. In another study, Newton, Billett and Ockerby ${ }^{[18]}$ reported that as students acquire increasing knowledge, they secured relationships with a broader network of nurses beyond those in a designated clinical educator or mentoring role.

Alternately, a diminished sense of belongingness in the clinical learning environment has been attributed to unreceptive milieus. The discord created by a disparity between students' personal and professional values, and those in the practice environment undermined belongingness ${ }^{[19,20]}$. Distress, anger, confusion, detachment, and disengagement in learning can occur in such situations.

The reviewed literature establishes an association between belongingness and the development of nursing student praxis. Overall, the positive learning outcomes identified are not disputed. Less is known, however, about how students actively seek belongingness in a clinical setting through their self-directed actions and interactions with others. The purpose of this study therefore, was to describe undergraduate students' perception of belongingness in clinical learning environments.

\section{Methods}

\subsection{Design}

Clinical learning occurs within larger social structures while students engage with others, attach meaning to subjective experiences, and attempt to make sense of their world. Charmaz's ${ }^{[21-24]}$ constructivist grounded theory approach was used to explicate students' actions and interactions in clinical learning environments for belongingness. Within this design, participants' explanations of their experiences are subject to inductive and comparative analysis to render a construction of reality. As Charmaz ${ }^{[22]}$ states, researchers are part of the world they study. As such, they construct a theoretical understanding through "involvements and interactions with people, perspectives, and research practices” (p. 10). In doing so, the researchers move back and forth between analysis and data collection to render an interpretative description of how participants' experiences were constructed. This study received ethical approval from the participating organizations.

\subsection{Setting and sample}

The setting for the study was a four year baccalaureate nursing program offered in multiple communities across Ontario, Canada. Students complete concurrent classroom and clinical experiences in both acute and community settings in each of the eight semesters of the program. The program, situated within the human educative paradigm as described by Bevis and Watson ${ }^{[25]}$, values interactions among students, course professors, clinical educators, patients, and unit-based nurses for learning and professional transformation. 
Sampling was completed in two phases. In phase one, purposive sampling was used to initially identify the students who were able to elucidate their perceptions of the topic of inquiry ${ }^{[26]}$, belongingness in the clinical environment. The sample of interest was students who were enrolled in the baccalaureate nursing program and had successfully completed at least five consecutive academic semesters during which they were supervised by an educator in the clinical learning environment. The study was introduced to third and fourth year students immediately following a scheduled nursing class. As a result, 14 students expressed their willingness to be interviewed about belongingness. During phase two, theoretical sampling was used to obtain data to explicate and delineate the dimensions that pertained to the development of a conceptual description ${ }^{[22,23]}$ of belongingness. Based on their articulated experiences of clinical belongingness, four students from the original sample and four new students were invited to respond to the developing dimensions of belongingness in an effort to co-construct the rendering of belongingness with the students.

\subsection{Data collection and analysis}

The two data collection strategies were individual interviewing and memo-writing. In constructed grounded theory, memo-writing is both a data collection and data analysis method ${ }^{[22]}$. Within this study, memo-writing was initiated after the first interview, and continued throughout the data collection process and extended into the analysis phase. To preserve anonymity of all students, socio-demographic data were intentionally not collected.

Individual Interviewing. Consistent with Charmaz's ${ }^{[22]}$ approach, data was collected through at least one semi-structured, audio-recorded interview with each participant. The length of the interview ranged from 60 to 90 minutes. Examples of questions used to elicit students' perceptions of belongingness in clinical settings included: "Tell me about a typical day in your clinical placement”; "Describe an exceptionally positive day in your clinical placement”; and "What and who, if anyone, influenced your experience in your clinical placement?” These questions were intentionally general to allow for a description of diverse perceptions and specific enough to allow for detailed elaboration about their perceptions ${ }^{[22]}$ of belongingness. Further, as recommended by Charmaz ${ }^{[22]}$, such questions avoided the imposition of preconceived notions of belongingness upon the students' reality of learning in the clinical setting. For the four students who agreed to a second interview and the four new students, data collection focused on a further exploration of the belongingness identified during preliminary data analysis. These students were intentionally not provided with a summary of the data from prior interviews. The focused questions however, integrated the actual language of earlier participants, such as "isolation" and "learn the rules". In addition, the phenomenon of interest was explicitly referred to as belongingness. This was undertaken to allow the participant and the interviewer to share language and promote a common frame of reference ${ }^{[22]}$. Two examples of questions used during this phase of data collection were "How do you ensure success when isolated from others in the clinical setting?" and, "Is there something else you think I should add to help me understand what belongingness in the clinical setting involves?”

Memo-writing. Using a free style approach, memo-writing initially captured a chronological account of the researcher's coding, category descriptions, data comparisons, and identification of unanswered questions to be pursued in subsequent interviews ${ }^{[23,27]}$. With each sequential interview, the memo-writing reflected evolving conceptual connections.

The interview data were transcribed verbatim. Data analysis was conducted simultaneously with data collection through the process of comparative analysis following the conventions established by Charmaz ${ }^{[22,28]}$. To construct a descriptive interpretation of the inter-related dimensions of belongingness in the clinical learning environment, data were subjected to labeling, coding, categorizing, and conceptualizing. A fundamental question the researchers asked was "What is happening in small segments of data?" [28]. In this study, a small segment of data referred to a sentence. Each sentence was assigned a descriptive label representative of its content. These labels were then compared with other data labels to identify similarities and differences allowing data labels to be grouped into common codes. Subsequently, codes were compared with codes to assemble larger data categories. The labels and codes associated with a single category were then reviewed to ensure a fit between each category and its constituent elements. Categories were then compared with categories by all researchers independently. Following discussion, concepts with discrete properties were identified. 
Finally, concepts were compared with concepts to describe inter-relationships. These concepts and their inter-relationships focused further data collection through theoretical sampling. Iterative data collection and analysis concluded when no further conceptual developments of belongingness in the clinical learning environment were identified.

\section{Results}

Seven of the 18 students were enrolled in the third year of the baccalaureate program. The remaining students were completing their final year of study. All students expressed a commitment to their professional development within the clinical learning environment. They wanted to experience the "proper ways" of knowing, being, and doing nursing.

The students described three dimensions of belongingness, positioning for belongingness; persevering for belongingness; and entering into belongingness. Belongingness was conceptualized as gaining entry into the nursing "atmosphere". This term was used by students to designate a privileged space, unique to each clinical setting. Within this space, students were granted access to "rich learning" and socialization opportunities in partnership with unit-based nurses. Belongingness was desired by many to further their nursing praxis. Upon entry into each new clinical learning environment, positioning for belongingness involved students' demonstration of their preparedness for clinical practice. A decision to optimize their learning and professional growth within the clinical setting involved persevering for belongingness. Students were cognizant that their performance was continually scrutinized by educators and unit-based nurses. Ultimately, entering into belongingness was predicated on unit-based nurses' evaluation of a student's competence and connectedness to others. Students who earned entry into this space were afforded richer privileged learning opportunities inclusive of knowledge exchange inaccessible outside of belongingness.

\subsection{Positioning for belongingness}

Within this first dimension, students described how they positioned themselves within each new clinical setting for belongingness. Purposeful positioning offered an opportunity for students to demonstrate their self-preparation to their clinical educator and unit-based nurses.

To meet weekly clinical expectations, preparation was perceived as both essential and "time consuming". For positioning in the clinical setting, students independently reviewed their patient assignments prior to arrival on the unit, developed evidence-informed plans of care, and anticipated questions to be asked by their clinical educator and unit-based nurses. The following student shared her insight regarding the importance of preparation prior to connecting with others in the clinical setting:

Preparation is a big thing for us. I'm thorough. I want to see the patient information. I'm a little anxious just in case I didn't cover everything. I get there 20 minutes early. I am always checking that everything is all right - even my shoes and name tag.

This example illustrates the student's commitment to fulfilling the preparation expected by her clinical educator such that she is positioned for belongingness.

In order to best demonstrate their preparation students were aware of the importance of being visible to their clinical educator and unit-based nurses. Students located themselves for inclusion in nursing activities by "introducing themselves", "using pleasantries to break the ice”, "asking questions”, and "going around and offering help”. A student shared her strategic efforts to make herself visible:

I learned to position myself so that I could hear everything that was being said during morning report. I make notes about the patient information being passed. I meet with my educator and seek out my assigned nurse to introduce myself. 
Within the clinical setting, students were assigned a component of one or more unit-based nurses' workload. Unit-based nurses who "actually acknowledged that students were assigned to them", promoted positioning for belongingness. Such acknowledgement validated their position as legitimate, yet novice clinicians who were prepared to assume a rightful place as learners within the unit. One student explained,

It is terrifying. I didn't know where to get equipment or where put things on the unit. It is amazing when you run into some nurses that remember what it was like to be a student. They take time to learn your name and want to hear from you. They want to interact with you ... to understand the needs of the patient. They help you try to learn, to keep everything safe and be more comfortable.

Not all nurses, however, were appraised as receptive to the presence of students in a unit. The following student shared how her positioning for belongingness was hindered through exclusion by some unit-based nurses. Being "pushed aside" was typified when told:

...you can only listen to morning report after we listen to it. This makes you feel uncomfortable. Uncomfortable to the point where we end up hiding on the unit in order to stay out of everyone's way. This makes us very insecure.

In addition to being physically marginalized, students described that at times, they felt invisible - "like a ghost", "like a burden on the system" and "unwanted" by the unit-based nurses. Subsequently, some students considered themselves as removed from full participation in patient care to the extent that "we are literately outside the door looking in barely able to see and know the patient's status.” This lack of opportunity to demonstrate their readiness for practice limited their positioning for belongingness in the clinical setting.

Students described the ideal of being positioned to demonstrate their preparedness for practice at the onset of each clinical day. As one student elaborated:

Right after the morning report I would talk with my clinical educator about my assignment for the day. I would go over what medications I was going to be giving and what they do. I would describe the patients' health challenges and that kind of thing. I'd start the day off with introducing myself to the patients and the nurses. I'd be ready to get started for the day.

\subsection{Persevering for belongingness}

In this second dimension, students described persevering for belongingness, a labour intensive undertaking for learning to learning. This is illustrated by the following:

I found that I had to work extremely hard and be outgoing all the time, all day long, on every clinical day. I had to take the initiative to put myself out there in order to make an impression on my clinical educator and the nurses so that I could get the best possible opportunities for learning.

Perseverance required initiative and endurance on the part of students to seek out positive opportunities for professional growth and refinement of their competencies. In particular, students sought learning partnerships with clinical educators and nurses that were perceived to be good role models. Students vigilantly observed other nurses for demonstrated evidence of competencies that they could mirror. As described by one student:

I would watch them [the nurses]. I would watch how she cared for patients and I'd kind of demonstrate the same style because I wanted to become more confident in my skills. 
Identification of a supportive other promoted their comfort in learning and desire for belongingness. In partnership with their educator, students' "worry" about their performance decreased. Knowing "where you both stand" assisted students to focus their energy. They were able to hear and reflect upon the critical appraisal of their evolving competencies. This is illustrated in the following statement:

To push it one step further it is important to be able to practice on real people like you learned in school and then get feedback about how you are doing so that you can get better and have a little bit of autonomy. So whether it was constructive criticism or commenting on the strengths about how I did, we were able to have that discussion openly.

Students were also aware that a clinical educator's negative evaluation about their performance could diminish their perseverance. As described by one student:

My clinical educator said, 'Oh you are too slow. You are never going to carry on a full-patient load.' She said it is because I wasn’t organized. I thought I was very organized. Her comments put a damper on my progression.

Diminished perseverance also occurred when students perceived their clinical educator to be inaccessible. As a result, students described practicing in isolation, an exhausting injustice, countering their preference to be connected to their clinical educator.

I was always trying to grab my educator. And she'd always say 'I'm busy right now. I'm busy.' I had to face it alone rather than getting help. No student should have to deal with abandonment while trying to learn new stuff especially if you have little experience and you are thrown into a setting. It is not easy. I still remember going home and being very upset because there was no such thing like help even though I tried to get some.

In such a context, belongingness became less likely, and for some, not desired. These students persevered just "to survive" the clinical experience not to seek belongingness.

Further, belongingness was not sought when students processed receipt of negative appraisal as personally threatening as opposed to growth producing. These students minimized their interactions with clinical educator and unit-based nurses as a strategy to protect their selfhood. The circumstances resulting in the choice not to pursue belongingness was described by the following student:

My patient was going to have a procedure done on the unit that I learned about in school but my clinical educator was on break. I didn't have to, but I asked the nurses if I could assist. They said, 'Sure.' But I hadn't completed everything that I needed to do before the physician arrived and he wasn't happy neither were the nurses. They laughed saying 'I was just the student, what can you expect.' It made me look incompetent. I realized that I wasn't really part of the team, I'm just on the outskirts. Now I'm definitely not as quick to jump in to do something unless I really have to. I definitely hold back, I'm more leery about working with the nurses.

This risk reduction strategy had implications for belongingness. Without perseverance, engagement in learning, dialoguing, and refining clinical competencies became a challenge.

\subsection{Entering into belongingness}

Students who desired belongingness made themselves accessible for assessment by unit-based nurses. The nurses would "judge” whether an individual student was a "good fit” with unit’s particular nursing atmosphere. Students believed that this assessment, whether positive or negative, could be influenced by the informal reports of other clinicians including their clinical educator. Students acknowledged that their clinical competency, ability to positively contribute to nursing 
care, and interpersonal skills were highly scrutinized as part of entering into belongingness. They believed that they had to "prove" that they were worthy of belongingness as this was granted to a select few as described by the following student:

The charge nurse told me I was doing a good job with my patients the last few weeks and I worked well with the other nurses. She asked if I'd be working tomorrow and invited me to attend nursing rounds with her. I couldn't believe she picked me out of all the students on the floor. It was great to hear that I was included in something special.

When the students' quest for belongingness culminated in the triumphant arrival at the nursing atmosphere, belongingness provided access to privileged professional relationships. Although aware of their status as a novice, they considered themselves "part of the nursing team," as illustrated by the following:

I felt that I was now working alongside the nurses, really working with them. They could see my potential. They gave me information and asked me questions which I could answer we worked through things together. I learned from them and they learned from me. They told me "there was no such thing as a stupid question.” I felt like I was contributing to the greater good.

Belongingness rendered them "valued", "accepted", and "regarded as a future colleague rather than just some student" placed on their unit. With inclusivity, students perceived that they were actively involved in the day-to-day realities of the profession which allowed them to have a sense of increasing contribution to patient care. For example,

...nurses were always involving me in their daily work. During the day they would say ' $I$ have something cool to show you, come with me.' Offering me opportunities was like being offered gold, and I felt like I made it. I really made it! It actually helped me to deliver quality patient care. More and more, I can stand on my own two feet and advocate for the patients.

Belongingness offered freedom to focus on their development of nursing praxis through professional socialization and access to "rich learning" experiences within the nursing atmosphere. As described by one student:

I'm not terrified of making a mistake when I'm working alongside the nurses. They watch out for me. They make sure I have a chance to learn and practice the knowledge of nursing. I'm not quite there yet, but when they talk and I don't understand, they simply explain it in another way. I've learned so much. Wow, this is the floor I definitely want to work on after graduation.

Earning entry into belongingness was not transferable between clinical practice areas. With each new clinical placement, students started a "new cycle" that involved positioning, progressing, and entering for belongingness if so desired. One student explained:

Every placement is a new beginning. You have to work to apply new knowledge and be evaluated on your performance by a new educator and new nurses in each placement. It is like restarting every time you get a new placement. It takes time to earn the nurses' trust in your abilities. Sometimes it happens, sometimes it doesn't. When you are on the perimeter, you try to stay out of everyone's way. It's horrible, you are terrified, but you still learn. When you are in though, it is great.

\section{Discussion}

Within each clinical practice setting, students acknowledged the existence of a unique nursing atmosphere. Belongingness was constituted by three dimensions including positioning, persevering and entering to into the nursing "atmosphere". Positioning for belongingness began with students' clinical preparation and demonstration of their readiness for clinical 
practice to their clinical educator and unit-based nurses. Strategic positioning and refinement of their clinical competencies fostered their perseverance for belongingness with the hope of entering the nursing atmosphere. Those students judged as worthy, based on the unit-based nurses' scrutiny of their clinical competence, contribution to nursing practice, and interpersonal skills, were granted entry into this privileged space. Those not achieving or seeking belongingness, continued to learn and practice at the periphery of the unit's nursing atmosphere. With belongingness, students were provided with experiential learning and socialization opportunities guided by unit-based nurses to support their development of praxis.

Previous research identified the value of inclusivity for student well-being and learning ${ }^{[18,19,29]}$. In addition, Gillespie ${ }^{[16]}$ suggested positive relationships between belonging and academic motivation. In light of the current study's findings, the desire for belongingness may enhance the quality of students' clinical preparation and their efforts to connect with nurses when in the practice setting. Preparation and connectedness with others, critical elements of positioning and persevering for belongingness, have the potential to advance the development of all students, regardless of whether they achieve entry into the nursing atmosphere or not. For those students who achieve entry into the nursing atmosphere, opportunities for further growth alongside unit-based nurses are available by virtue of their earned belongingness.

Based on this study's findings, preparing for clinical is foundational to positioning for belongingness. Completing preparatory work, however, not only requires clearly articulated program expectations, but also student self-directedness to identify and fulfill their specific learning needs ${ }^{[30]}$. According to Knowles ${ }^{[31]}$ self-directedness predisposes students to developing insight into and ownership of their learning. As such, academic and clinical educators who facilitate the development of student self-directedness, indirectly support student clinical preparedness, which ultimately assists with positioning for belongingness. It is suggested that self-directedness be introduced early and emphasized throughout undergraduate nursing programs to encourage student accountability for optimizing learning. Pryce-Miller ${ }^{[32]}$ found that first year nursing students can be uncertain about their role as a self-directed learner and therefore require guidance from their educators and their program.

In addition to being prepared for clinical experiences, the pathway to belongingness is facilitated through students' meaningful connections with their clinical educator and unit-based nurses. This is supported by the professional standard that all nurses have an obligation to participate in the socialization and development of the students' competencies needed for safe, ethical and effective practice ${ }^{[33]}$. In order to be positioned for belongingness, students described their use of social conventions as the typical approach for the initiation of rapport with unit-based nurses. Educators that foster the development of a wider range of communication and interpersonal skills can assist students as they attempt to establish and maintain collegial relationships ${ }^{[34]}$. In this study, students identified that connections with unit-based nurses allowed them to partner for guided learning and persevere for belongingness in each clinical placement. Appreciating the expanding responsibilities within the discipline of nursing, learning facilitated through partnerships between novices and experts is consistent with a safe and emancipatory approach to nursing education ${ }^{[35]}$.

Commitment to achieving belongingness was mobilized through refinement of clinical competencies supported by formative feedback from clinical educators and unit-based nurses. As supported by previous research ${ }^{[36,37]}$, the students in this study expressed a desired to be partnered with knowledgeable and approachable clinical educators who were available to support their learning within an invitational clinical setting. Collectively, these findings encourage clinical educators to showcase their competence and participate in ongoing professional development initiatives to support their teaching role. In addition, unit-based nurses are encouraged to consider the importance of their role in generating a learning culture within the practice setting. Idczak ${ }^{[9]}$ stated that in supportive clinical learning environments, nursing students became more connected to their role as a nurse.

In this study, students articulated the importance of external validation of their competency as they learn to nurse in the clinical setting. More specifically students described the importance of nurses' acknowledgement of their evolving 
competencies in order to gain access to rich learning and patient care opportunities affording within the nursing atmosphere, that is, belongingness. In order to appropriately assess student readiness for belongingness, unit-based nurses require an awareness of the learning needs and anticipated outcomes for each level of student who enters their clinical environment. Such knowledge would not only assist unit-based nurses in determining eligibility for entry into their nursing atmosphere, but also provide direction in how to best support and critically appraise their growth. To this end, it has been recommended that academic and clinical educators provide unit-based nurses with a profile of student competencies and learning needs at the onset of each clinical rotation ${ }^{[38]}$. The provision of appropriate learning opportunities and credible feedback would promote student self-reflection for planned progression through preparing, persevering and entering into belongingness.

\section{Conclusion}

In summary, this study represents one construction of belongingness in clinical learning environments from the perspective of third and fourth year baccalaureate nursing students. Student belongingness, as privileged entry into the unique nursing atmosphere of a given clinical setting, demands demonstrated competency and relational connectedness for engagement in optimal learning opportunities. Study participants, however, were limited to senior students, thereby developing a unidimensional perspective. Future research that includes the perspectives of junior nursing students, clinical educators and unit-based nurses relative to process of securing belongingness could extend this study's findings for the development a fuller theoretical rendering of this phenomenon.

\section{Competing interests}

The authors declare that they have no competing interest.

\section{Authors' contributions}

Each author participated in the conception and methods of this study, manuscript preparation and its approval.

\section{References}

[1] Berntsen K, Bjork IT. Nursing students’ perceptions of the clinical learning environment in nursing homes. Journal of Nursing Education. 2010; 49(1): 17-22. PMid:19731888 http://dx.doi.org/10.3928/01484834-20090828-06

[2] Cederbaum J, Klusaritz HA. Clinical instruction: Using the strengths-based approach with nursing students. Journal of Nursing Education. 2009; 48(8): 422-428. PMid:19681530 http://dx.doi.org/10.3928/01484834-20090518-01

[3] Levett-Jones T, Lathlean J, Maguire J, McMillan M. Belongingness: A critique of the concept and implications for nursing education. Nurse Education. 2007; 27: 210-218. PMid:16828935 http://dx.doi.org/10.1016/j.nedt.2006.05.001

[4] Booker KC. Likeness, comfort, and tolerance: Examining African American adolescents' sense of school belonging. The Urban Review. 2007; 39(3): 301-317. http://dx.doi.org/10.1007/s11256-007-0053-y

[5] Osterman KF. Students' need for belonging in the school community. Review of Education Research. 2000; $70(3)$ : 323-367. http://dx.doi.org/10.3102/00346543070003323

[6] Van Ryzin MJ, Gravel AA, Roseth CJ. Autonomy, belongingness, and engagement in school as contributors to adolescent psychological well-being. Journal of Youth Adolescence. 2009; 38: 1-12. PMid:19636787 http://dx.doi.org/10.1007/s10964-007-9257-4

[7] Freeman TM, Anderman LH, Jensen JM. Sense of belonging in college freshman at the classroom and campus level. The Journal of Experimental Education. 2007; 75(3): 203-220. http://dx.doi.org/10.3200/JEXE.75.3.203-220

[8] Bradbury-Jones C, Sambrook S. Irvine F. Empowerment and being valued: A phenomenological study of nursing students' experiences of clinical practice. Nursing Education Today. 2011; 31(4): 368-372. PMid:20696505 http://dx.doi.org/10.1016/j.nedt.2010.07.008

[9] Idczak SE. I am a nurse: Nursing students learn the art and science of nursing. Nursing Education Perspectives. 2007; 28(2): 66-71. PMid:17486794

[10] Josen E, Melender H. Finnish and Swedish nursing students' experiences of their first clinical practice placement: A qualitative study. Nurse Education Today. 2013; 33: 297-302. PMid:22795745 http://dx.doi.org/10.1016/j.nedt.2012.06.012

[11] Kim M, Jung D. Reliability and validity of the Korean version of Belongingness Scale-Clinical Placement Experience (BS-CPE). Asian Nursing Research. 2012; 37: 137-142. http://dx.doi.org/10.1016/j.anr.2012.10.002 
[12] Levett-Jones T, Lathlean J. Belongingness: A prerequisite for nursing students' clinical learning. Nurse Education in Practice. 2008; 8: 103-111. PMid:18291327 http://dx.doi.org/10.1016/j.nepr.2007.04.003

[13] Levett-Jones T, Lathlean J. Belongingness: A montage of nursing students's stories of their clinical placement experiences. Contemporary Nurse. 2007; 24: 162-174. http://dx.doi.org/10.5172/conu.2007.24.2.162

[14] Levett-Jones T, Lathlean J, Higgins I, Mc Millan M. Development and psychometric testing of the belongingness scale-Clinical placement experience: An international comparative study. Collegian. 2009; 16: 153-162. PMid:19831149 http://dx.doi.org/10.1016/j.colegn.2009.04.004

[15] Grealish L, Ranse K. An exploratory study of first year nursing students’ learning in the clinical workplace. Contemporary Nurse. 2009; 33(1): 80-92. http://dx.doi.org/10.5172/conu.33.1.80

[16] Gillespie M. Student-teacher connection in clinical nursing education. Journal of Advanced Nursing. 2002; 37(6): 566-576. PMid:11879421 http://dx.doi.org/10.1046/j.1365-2648.2002.02131.x

[17] Elcigil A, Sari HY. Students' opinions about and expectations of effective nursing clinical mentors. Journal of Nursing Education. 2008; 47(3): 118-123. http://dx.doi.org/10.3928/01484834-20080301-07

[18] Newton JM, Billett S, Ockerby CM. Journeying through clinical placement-An examination of six student cases. Nurse Education Today. 2009; 29: 630-634. PMid:19231041 http://dx.doi.org/10.1016/j.nedt.2009.01.009

[19] Levett-Jones T, Lathlean J. The ascent to competence conceptual framework: an outcome of a study of belongingness. Journal of Clinical Nursing. 2009; 18: 2870-2879. PMid:19220619 http://dx.doi.org/10.1111/j.1365-2702.2008.02593.x

[20] Anthony M. Nursing students' experience with incivility in clinical education. Journal of Nursing Education. 2011; 50(3): 140-144. PMid:21323254 http://dx.doi.org/10.3928/01484834-20110131-04

[21] Charmaz K. A constructivist grounded theory analysis of losing and regaining a valued self. In Five ways of doing qualitative analysis. F. J. K. Wertz, K. Charmaz, LM. McMullen, R. Hosselson, R. Anderson, E. McSpadden, eds, New York: Guilford Press, 2011, 165-204.

[22] Charmaz K. Constructing grounded theory: A practical guide through qualitative analysis. London, England: Sage Publications, 2006.

[23] Charmaz, K. Shifting the grounds: Constructivist grounded theory methods. In J.M. Morse, P. Noerager Stern, J. Corbin, B. Bowers, K. Charmaz, A. E. Clarke. Developing grounded theory: The second generation. Walnut Creek: Left Coast Press, 2009, 127-154.

[24] Schreiber, R.S, Martin, W. New directions in grounded theory. In C. Tatano Beck. Routhledge International Handbook of Qualitative Nursing Research. London: Routledge, 2013, 183-202.

[25] Bevis O, Watson J. Towards a caring curriculum: A new pedagogy for nursing. Sudbury, MA: Jones and Bartlett, 2000.

[26] Morse JM. Qualitative nursing research. London: Sage, 1991.

[27] Montgomery P, Bailey P. Field notes and theoretical memos in grounded theory. Western Journal of Nursing Research. 2007; $29(1)$ : 65-79. PMid:17228061 http://dx.doi.org/10.1177/0193945906292557

[28] Charmaz, K. Grounded theory methods in social justice research. In N.K. Denzin, Y.S. Lincoln. Strategies of Qualitative Inquiry. Los Angles: Sage, 2013, 291-336.

[29] Ranse K, Grealish L. Nursing students’ perceptions of learning in the clinical setting of the dedicated education unit. Journal of Advanced Nursing. 2007; 58(2): 171-179. PMid:17445020 http://dx.doi.org/10.1111/j.1365-2648.2007.04220.x

[30] Levett-Jones T. Self-directed learning: Implications and limitations for undergraduate nursing education. Nursing Education Today. 2005; 25: 363-368. PMid:15894411 http://dx.doi.org/10.1016/j.nedt.2005.03.003

[31] Knowles MS. Self-directed learning: A guide for learners and teachers. New York: Association Press, 1975.

[32] Pryce-Miller M. Are first year undergraduate student nurses prepared for self directed learning? Nursing Times. 2010; 106: 21-4. PMid:21192595

[33] College of Nurses of Ontario. Practice Guideline: Supporting Learning. Toronto, Ontario: Author, 2009. Available from: http://www.cno.org/Global/docs/prac/44034_SupportLearners.pdf

[34] College of Nurses of Ontario. Professional Standards. Toronto, Ontario: Author, 2009. Available from: http://www.cno.org/Global/docs/prac/41034_Ethics.pdf

[35] Benner P, Sutphen M, Leonard V, Day L. Educating nursing: A call for radical transformation. California: Jossey-Boss, 2010.

[36] Hanson KJ, Stenvig TE. The good clinical nursing educator and the baccalaureate nursing clinical experience: Attributes and praxis. Journal of Nursing Education. 2008; 47(1): 38-42. http://dx.doi.org/10.3928/01484834-20080101-04

[37] Newton JM, Billett S, Jolly B, Ockerby C. Preparing nurses and engaging preceptors. In Developing learning professionals: Integrating experiences in university and practice settings. S. Billett \& A. Henderson, eds. Netherlands: Springer, 2011, 43-57. http://dx.doi.org/10.1007/978-90-481-3937-8_3

[38] Levett-Jones T,Gersbach A, Roche J. Implementing a clinical competency assessment model that promotes critical reflection and ensures nursing graduates’ readiness for professional practice. Nursing Education in Practice. 2011; 11: 64-69. PMid:20727825 http://dx.doi.org/10.1016/j.nepr.2010.07.004 